This item was submitted to Loughborough's Research Repository by the author.

Items in Figshare are protected by copyright, with all rights reserved, unless otherwise indicated.

\title{
Atmospheric glow discharges from the high-frequency to very high-frequency bands
}

PLEASE CITE THE PUBLISHED VERSION

PUBLISHER

(c) American Institute of Physics

\section{VERSION}

VoR (Version of Record)

\section{LICENCE}

CC BY-NC-ND 4.0

\section{REPOSITORY RECORD}

Walsh, James L., Felipe Iza, and Michael G. Kong. 2019. "Atmospheric Glow Discharges from the Highfrequency to Very High-frequency Bands". figshare. https://hdl.handle.net/2134/5200. 
This item was submitted to Loughborough's Institutional Repository (https://dspace.lboro.ac.uk/) by the author and is made available under the following Creative Commons Licence conditions.

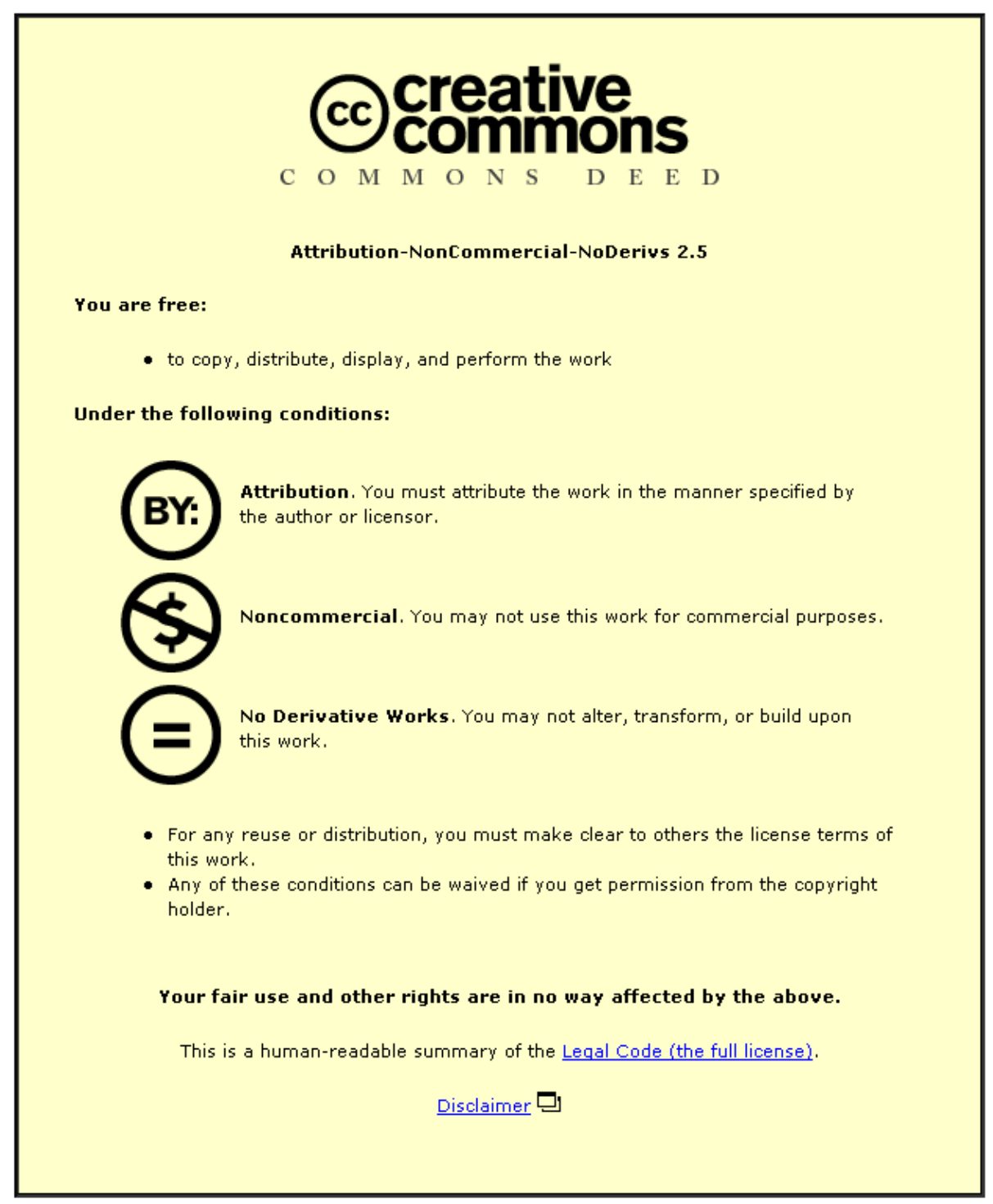

For the full text of this licence, please go to: http://creativecommons.org/licenses/by-nc-nd/2.5/ 


\title{
Atmospheric glow discharges from the high-frequency to very high-frequency bands
}

\author{
J. L. Walsh, F. Iza, and M. G. Kong ${ }^{\text {a) }}$ \\ Department of Electronic and Electrical Engineering, Loughborough University, Loughborough, \\ Leicestershire LE11 3TU, United Kingdom
}

(Received 24 July 2008; accepted 1 December 2008; published online 23 December 2008)

\begin{abstract}
This letter reports an experimental investigation of an atmospheric glow discharge in both the high-frequency (HF) band of 3-30 MHz and the very high frequency band of 30-300 MHz. At constant input power, increased frequency is found to change little the electron density and to reduce slightly the electron excitation temperature. Significantly, an eightfold frequency increase from 20 to $80 \mathrm{MHz}$ leads to a 20 -fold increase in the maximum plasma power without plasma constriction. The maximum power density of $355 \mathrm{~W} / \mathrm{cm}^{3}$ achieved at $80 \mathrm{MHz}$ is far greater than those reported in the HF band. (C) 2008 American Institute of Physics. [DOI: 10.1063/1.3052857]
\end{abstract}

Radio-frequency (rf) excitation is commonly used to generate glow discharges over a wide range of gas pressures. Typically, rf discharges used in industrial processes, such as silicon wafer etching and plasma assisted chemical vapor deposition, tend to operate in a low-pressure regime. ${ }^{1}$ Recent studies have focused on the use of atmospheric pressure glow discharges (APGDs) as an alternative to low-pressure discharges for materials processing applications, ${ }^{2-4}$ since they offer the potential of considerable cost saving by discarding the need for complex vacuum equipments. Compared to low-pressure discharges, homogeneous APGDs are much more susceptible to rapid transition into a constricted $\gamma$ mode when excited in the common high-frequency (HF) band of 3-30 MHz. ${ }^{5-9}$ By reducing the input rf power, it is possible to operate in the more stable $\alpha$ mode but at the expense of low electron densities thus compromising their application efficiency. ${ }^{10}$ One technique to achieve high plasma density without plasma constriction is to add a dielectric barrier to the electrodes so as to control the growth of the discharge current. ${ }^{11-13}$ Its drawbacks are, however, an increase in the breakdown voltage and a possible drift in plasma properties when plasma chemistry is harsh and contaminates the dielectric material. Instead of modifying physical structure of the electrodes such as using dielectric barriers, it is possible to facilitate temporal modification of plasma dynamics, for example, by changing the excitation frequency. Both simulation and experimental results show that increasing excitation frequency from 6.78 to $27.12 \mathrm{MHz}$ markedly elevates the maximum current density without plasma constriction. ${ }^{14,15}$ This prompts the question of the scope of such benefits when the frequency is pushed into the very higher frequency (VHF) band of 30-300 MHz. ${ }^{16}$ While the use of VHF excitation is known to be beneficial in lowpressure discharges, ${ }^{1}$ its benefits to APGDs are largely unknown. The objective of this work is to show experimentally that increasing excitation frequency significantly enhances APGD stability with much greater current and power densities.

The apparatus used in this investigation consisted of two metallic, water cooled electrodes, each with a $2 \mathrm{~cm}$ diameter

\footnotetext{
${ }^{\text {a) }}$ Author to whom correspondence should be addressed. Electronic mail: m.g.kong@lboro.ac.uk.
}

and separated by $1 \mathrm{~mm}$. Helium gas was fed into the electrode housing unit using a mass flow controller. One electrode was grounded while the input rf power was fed to the other via a matching network. A Pearson $2877200 \mathrm{MHz}$ current probe and Tektronix P5100 $250 \mathrm{MHz}$ voltage probe were connected directly to the powered electrode to capture current and voltage waveforms. The difficulties associated with accurate electrical measurements of $\mathrm{rf}$ discharges particularly in the VHF band ${ }^{4,17}$ were addressed by minimizing stray inductance within the external circuitry and by employing a calibration procedure to ensure accurate phase and power measurements. ${ }^{17}$ Optical emission spectra were obtained using an Andor Shamrock spectrometer with a grating of 2400 grooves $/ \mathrm{mm}$ and plasma images were captured using an Andor iStar iCCD camera.

Figure 1 shows the current-voltage characteristics (CVCs) of a rf APGD generated at 20, 40, and $60 \mathrm{MHz}$. At each frequency, a linear prebreakdown region which is entirely attributed to the displacement current is marked with a dashed line in Fig. 1. At the point of gas breakdown, a plasma was formed within the gas gap causing an impedance change. This is reflected in the CVC as a change in the gradient of each curve. Immediately after breakdown, a low intensity and volumetric $\alpha$ mode discharge having a positive differential impedance was produced and the phase angle between current and voltage reduced from $90^{\circ}$, indicating the presence of both resistive (plasma bulk region) and capaci-

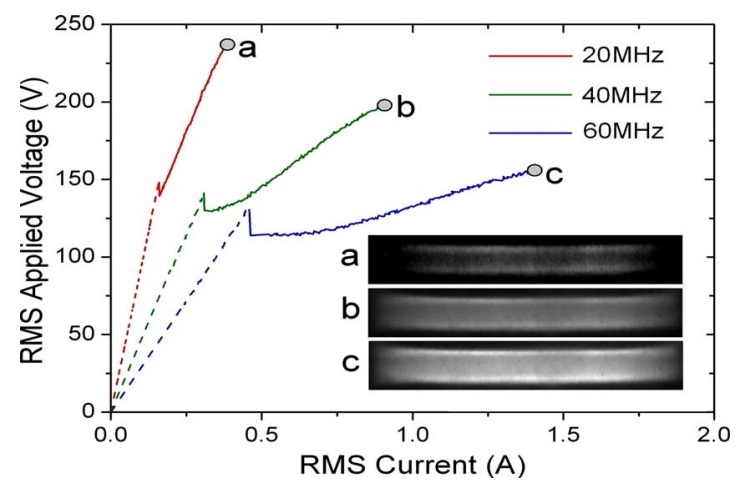

FIG. 1. (Color online) Current-voltage characteristics of rf APGD at 20, 40, and $60 \mathrm{MHz}$. Normalized iCCD images highlight plasma structure just before the APGD becomes unstable. 


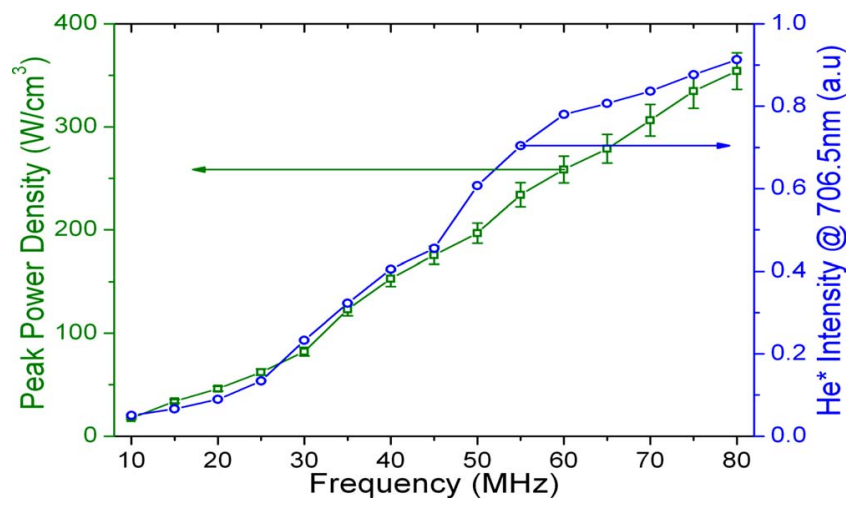

FIG. 2. (Color online) Frequency dependence of the peak dissipated rf power density and the helium $3{ }^{3} S_{1}$ emission intensity at $706.5 \mathrm{~nm}$.

tive (sheath region) impedances. As the input power was increased, it was observed that the capacitive impedance decreased and the sheath region shrank in size. It is known that with sufficient input power the sheath region could undergo an abrupt collapse thus causing the discharge to enter the less stable $\gamma$ mode. $^{5-9}$ In the $20 \mathrm{MHz}$ case, point $a$ marks the $\alpha$ $-\gamma$ mode transition beyond which increasing input rf power was found to constrict the discharge into a bright plasma column typically less than $1 \mathrm{~mm}$ in diameter. In the 40 and $60 \mathrm{MHz}$ cases, points $b$ and $c$ indicate plasma conditions under which the discharge became radially inhomogeneous, consisting of an optically intense channel surrounded by a weak but expansive and diffuse region. Therefore, points $a$, $b$, and $c$ mark the maximum permissible current for plasma stability, and Fig. 1 shows clearly its 3.5-fold increase from 0.4 to 1.4 A with the frequency increasing from 20 to 60 $\mathrm{MHz}$. It is worth mentioning that the breakdown voltage decreases with increasing frequency in Fig. 1.

Also shown in Fig. 1 is a series of iCCD images taken with a $1 \mu$ s exposure time at points $a, b$, and $c$. The intensity scale of each image is normalized to facilitate a direct comparison of the discharge intensity at each frequency. As expected, the $60 \mathrm{MHz}$ case is the most intense with its emission intensity being 1.6 and 6 times, respectively, the intensity in the 40 and $20 \mathrm{MHz}$ cases. With the frequency tripled to 60 $\mathrm{MHz}$ from $20 \mathrm{MHz}$, the sixfold increase in the emission intensity is higher than that in the maximum permissible current (3.5-fold). These results demonstrate clearly that the use of the VHF band pushes the plasma stability limit very effectively toward high discharge current and intense optical emission without plasma constriction, both of which are likely to translate into a high application efficiency.

Figure 2 shows the fuller benefits of VHF APGD with the frequency dependence of the maximum dissipated power density without plasma constriction. By increasing the frequency from 10 to $30 \mathrm{MHz}$, the maximum permissible power density increases from 17.6 to $82 \mathrm{~W} / \mathrm{cm}^{3}$ and a further increase in frequency to $80 \mathrm{MHz}$ raises the maximum power density to $355 \mathrm{~W} / \mathrm{cm}^{3}$. Consequently, an eightfold increase in frequency results in a 20 -fold increase in the maximum power density thus demonstrating the clear advantage of VHF operation. It is worth mentioning that $355 \mathrm{~W} / \mathrm{cm}^{3}$ is much higher than the maximum power density of $150 \mathrm{~W} / \mathrm{cm}^{3}$ reported so far of parallel-plate $\mathrm{rf}$ APGD at $13.56 \mathrm{MHz}{ }^{18}$ To support this further, we considered the $\mathrm{He}\left(3{ }^{3} S_{1} \rightarrow 2{ }^{3} P_{0,1,2}\right)$ transition at $706.5 \mathrm{~nm}$ which is known

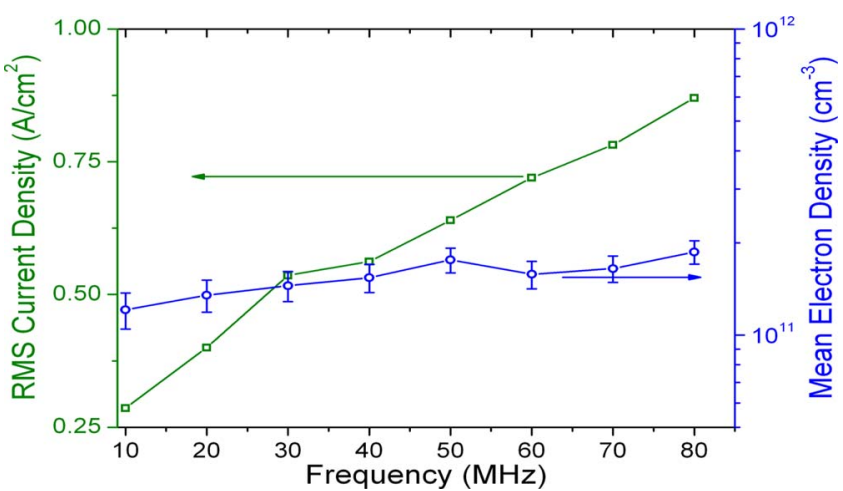

FIG. 3. (Color online) Frequency dependence of the current density and the electron density at a constant input power of $45 \mathrm{~W} / \mathrm{cm}^{3}$.

to be a good indication of the presence of either electrons with energies above $2.9 \mathrm{eV}$ or $\mathrm{He}_{2}^{+}\left(v^{*}\right)$ and low energy electrons. ${ }^{19}$ As the frequency increases from 10 to $80 \mathrm{MHz}$, the $706.5 \mathrm{~nm}$ emission intensity increases by 19 -fold, indicating an increase in either electron density or electron temperature, both of which are likely to enhance application efficiency. Also worth noting is the similarity in the increase in the maximum power density and in the emission intensity at $706.5 \mathrm{~nm}$.

To bring out more the underpinning physics of VHF APGD, Fig. 3 shows the measured current density as a function of frequency at a fixed rf power of $45 \mathrm{~W} / \mathrm{cm}^{3}$. With the power held constant while increasing the frequency, the current increases and the operating voltage decreases. From current, voltage, and phase measurements, it is possible to obtain the mean electron density in the plasma bulk using a simplified model of the discharge consisting of a bulk resistance $R_{b}$ and a series sheath capacitance $X_{s}{ }^{6,20}$ The reactive and resistive elements of the discharge were determined by $X_{s}=V_{p} I_{p} \sin \theta$ and $R_{b}=V_{p} I_{p} \cos \theta$, respectively, where $V_{p}, I_{p}$, and $\theta$ are, respectively, the peak applied voltage, the peak current, and the current-voltage phase angle. From the sheath reactance, the sheath capacitance $C_{s}=1 / \omega X_{s}$ was used to determine the sheath thickness $\left(d_{s}\right)$ assuming a collisional sheath of $d_{s}=1.52 \varepsilon_{0} A / C_{s}{ }^{1}$, where $A$ is the electrode area. The bulk voltage $V_{b}=R_{b} I_{p}$ was then used to estimate the spaceaveraged electric field in the bulk plasma $E_{b}=V_{b} /\left(d-d_{s}\right)$ with $d=1 \mathrm{~mm}$ being the electrode gap. Finally, the electron density was estimated using $n_{e}=\left(J / E_{b}\right) /\left(e \mu_{e}\right),{ }^{6,20}$ where $\mu_{e}$ $=1132 \mathrm{~cm}^{2} / \mathrm{V} \mathrm{s}$ is the electron mobility in atmospheric pressure helium and $e$ is the electron charge. As shown in Fig. 3, the electron density remains almost constant at a constant $\mathrm{rf}$ power regardless of the excitation frequency. Similar behavior has been observed in some low-pressure discharges, ${ }^{21}$ although the underpinning physics is unlikely to be the same and this will be addressed in a future note.

The amount of excited plasma species depends on both electron density and electron temperature. To estimate the electron temperature, optical emission spectroscopy was used. A $0.1 \%$ argon trace gas was added into the helium feed gas and a Boltzmann plot was created from the emission of relevant Ar I and Ar II lines. ${ }^{22}$ Figure 4 shows the frequency dependence of $T_{\mathrm{ex}}$ at a constant input power of $45 \mathrm{~W} / \mathrm{cm}^{3}$. From 30 to $80 \mathrm{MHz}$, the excitation temperature was found to decrease slightly from 0.95 to $0.917 \mathrm{eV}$, a $3.5 \%$ reduction. This is similar to that observed at lower pressures where it is 


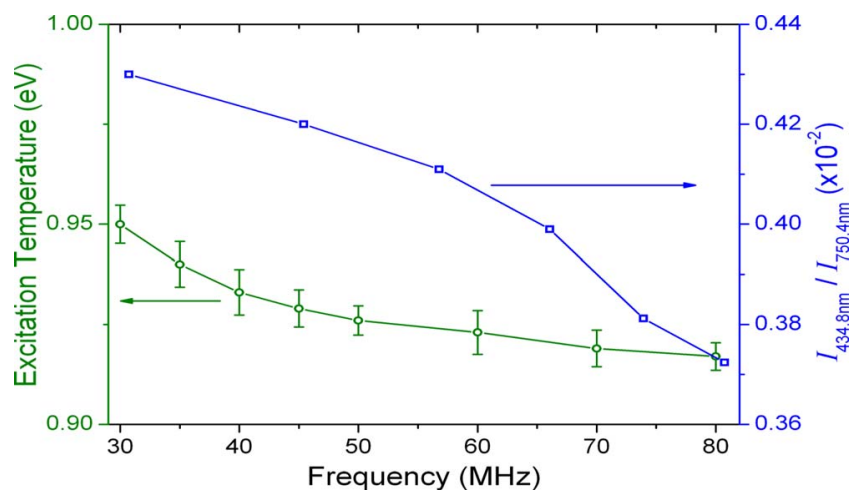

FIG. 4. (Color online) Frequency dependence of the excited electron temperature and the argon line ratio at 434.8 and $750.4 \mathrm{~nm}$ at a constant power density of $45 \mathrm{~W} / \mathrm{cm}^{3}$.

shown that the electron temperature undergoes modest reduction in the $10-50 \mathrm{MHz}$ range. ${ }^{23}$ To gain an indication of the electron energy distribution function, an emission lineratio method was employed. ${ }^{24}$ Electron impact excitation of $\operatorname{Ar}\left({ }^{1} S_{0}\right)$ by an electron with energies greater than $13.5 \mathrm{eV}$ produces $\operatorname{Ar}\left(2 P_{1}\right)$ which rapidly decays to $\operatorname{Ar}\left(1 s_{2}\right)$ producing a photon at $750.4 \mathrm{~nm}$; observation of this line gives an indication as to the number of electrons with energies above 13.5 $\mathrm{eV}$. Electron impact excitation of $\operatorname{Ar}\left({ }^{1} S_{0}\right)$ by an electron with energies above $35.3 \mathrm{eV}$ produces $\operatorname{Ar}^{+}\left(4 p^{4} D_{7 / 2}\right)$ which decays to $\operatorname{Ar}^{+}\left(4_{S}{ }^{4} P_{5 / 2}\right)$ producing a photon at $434.8 \mathrm{~nm}$. Consequently, the ratio of the two lines gives an indication as to the proportion of high energy electrons with respect to electrons with modest energy. Figure 4 suggests a reduction of about $13 \%$ in the $434.8 \mathrm{~nm} / 750.4 \mathrm{~nm}$ line ratio with increasing frequency, indicating a reduction in the proportion of high energy electrons. ${ }^{24}$ While the Boltzmann plot and the line-ratio methods used in Fig. 4 have scope for more detailed analysis, the consistency in the reduction in $T_{\mathrm{ex}}$ and the $434.8 \mathrm{~nm} / 705.4 \mathrm{~nm}$ line ratio suggests that an increase in the excitation frequency modestly reduces the proportion of high energy electrons at constant rf power.

In conclusion, this study has demonstrated that VHF excitation of rf APGD introduces an enhanced level of stability that is inaccessible at lower frequencies. With a constant $\mathrm{rf}$ power, it has been shown that electron density remains almost constant regardless of excitation frequency and the pro- portion of high energy electrons is likely to reduce modestly. These offer interesting similarity and contrast to those found in low-pressure VHF discharges. Significantly an eightfold frequency increase into the VHF band expands considerably the plasma stability range by facilitating a 20 -fold increase in the maximum permissible power density. This allows the generation of homogeneous rf APGD with very high plasma densities and makes it possible to achieve a step change in their current application efficiency.

${ }^{1}$ M. A. Lieberman and A. J. Lichtenberg, Principles of Plasma Discharges, 2nd ed. (Wiley, Hoboken, NJ, 2005).

${ }^{2}$ C. Sarra-Bournet, S. Turgeon, D. Mantovani, and G. Laroche, Plasma Processes Polym. 3, 506 (2006).

${ }^{3}$ A. Ladwig, S. Babayan, M. Smith, M. Hester, W. Highland, R. Koch, and R. Hicks, Surf. Coat. Technol. 201, 6460 (2007).

${ }^{4}$ V. Leveille and S. Coulombe, Meas. Sci. Technol. 17, 3027 (2006).

${ }^{5}$ J. Shi and M. G. Kong, IEEE Trans. Plasma Sci. 33, 624 (2005).

${ }^{6}$ X. Yang, M. Moravej, G. R. Nowling, S. E. Babayan, J. Penelon, J. P. Chang, and R. F. Hicks, Plasma Sources Sci. Technol. 14, 314 (2005).

${ }^{7}$ S. Y. Moon, J. K. Rhee, D. B. Kim, and W. Choe, Phys. Plasmas 13, 033502 (2006).

${ }^{8}$ J. J. Shi, D. W. Liu, and M. G. Kong, Appl. Phys. Lett. 90, 031505 (2007).

${ }^{9}$ H. P. Li, W. T. Sun, H. B. Wang, G. Li, and C. Y. Bao, Plasma Chem. Plasma Process. 27, 529 (2007).

${ }^{10}$ J. J. Shi and M. G. Kong, J. Appl. Phys. 97, 023306 (2005).

${ }^{11}$ L. Baars-Hibbe, P. Sichler, C. Schrader, C. Geßner, K. H. Gericke, and S. Büttgenbach, Surf. Coat. Technol. 174-175, 519 (2003).

${ }^{12}$ J. J. Shi and M. G. Kong, Appl. Phys. Lett. 89, 081502 (2006).

${ }^{13}$ S. Y. Moon, J. W. Han, and W. Choe, Thin Solid Films 506-507, 355 (2006).

${ }^{14}$ J. J. Shi and M. G. Kong, Appl. Phys. Lett. 87, 201501 (2005).

${ }^{15}$ J. J. Shi, D. W. Liu, and M. G. Kong, IEEE Trans. Plasma Sci. 35, 137 (2007).

${ }^{16}$ J. L.Walsh, Y. T. Zhang, F. Iza, and M. G. Kong, Appl. Phys. Lett. 93, 221505 (2008).

${ }^{17}$ N. Spiliopoulos, D. Mataras, and D. E. Rapakoulias, J. Vac. Sci. Technol. A 14, 2757 (1996).

${ }^{18}$ M. Moravej, X. Yang, R. F. Hicks, J. Penelon, and S. E. Babayan, J. Appl. Phys. 99, 093305 (2006).

${ }^{19}$ G. Nersisyan and W. G. Graham, Plasma Sources Sci. Technol. 13, 582 (2004).

${ }^{20}$ J. W. Walsh and M. G. Kong, Appl. Phys. Lett. 91, 251504 (2007).

${ }^{21}$ S. K. Ahn, S. J. You, and H. Y. Chang, Appl. Phys. Lett. 89, 16 (2006).

${ }^{22}$ S. Forster, C. Mohr, and W. Viol, Surf. Coat. Technol. 200, 827 (2005).

${ }^{23}$ Y. Takeuchi, H. Mashima, M. Murata, S. Uchino, and Y. Kawai, Surf Coat. Technol. 142-144, 52 (2001).

${ }^{24}$ M. Ishimaru, T. Ohba, T. Ohmori, T. Yagisawa, T. Kitajima, and T. Makabe, Appl. Phys. Lett. 92, 071501 (2008). 